\title{
Diversity and Human Resource Management with the Mediation Role of Inclusion: Evidence from Higher Education Institutions, Pakistan
}

\author{
Abdul Ghafar Khan \\ Mohd-Ud- Islamic University \\ Nerian Shrif AJ\&K \\ Pakistan \\ Muhammad Yousaf Raza \\ School of Management \\ Xiamen University Fujian \\ 3600, PR China \\ Aumbareen Khan \\ University of Science and Technology \\ Kohat \\ Arif Ullah \\ Preston University Main Campus Kohat \\ Pakistan
}

\begin{abstract}
This study aimed to checked the relationship between diversity and human resource management in higher academic institutions. In addition, we explored the effect of these mediating factors which contributes and have an impact on traditional human resource management process which will enable the leaders to manage this diversity so challenges could be handled with care and turned into opportunities. A conceptual model is developed which shows the hypothetical relationship between organizational culture, HR practices and employees' satisfaction along with the mediating role of inclusion. This research has both academic and practical implications. On academic level, it is going to study the mediating role of diversity on organizational culture and also the mediating role of inclusion on employee performance 'in the overall HRM process.
\end{abstract}

Key words: Cultural Dimensions, Environment, human resource management diversification.

\section{Introduction}

Organization is a vast subject to be studied. It has so many levels and dimensions from administrative to processes, from top to tactical level and from pure materials to human oriented are being investigated for a longer period of time. Organizational theory has been developed with a passage of time and a large number of scholars have contributed in this regard. Hierarchical culture and its relationship with HR practices and job satisfaction has also been ahot topic investigated by many scholars around the globe according to their local needs and situations.(A. G. Khan, 2015). For the last few years, relationship between diversity, HR practices and employees' job satisfaction is the centre of attention.(Böhm, Kunze, \& Bruch, 2014; Downey, Werff, Thomas, \& Plaut, 2015; Guillaume, Dawson, Woods, Sacramento, \& West, 2013; Richard A. Posthuma, Ayub, \& Jehn, 2014; Stazyk, Davis, \& Liang, 2012), diversity and emotions (Ashikali \& Groeneveld, 2015; Ayoko \& Konrad, 2012; Chiao, 2015; Guillaume et al., 2013), role of inclusion in diversity management (Ayoko \& Konrad, 2012; Boccagni, 2015; Downey et al., 2015; Theodorakopoulos \& Budhwar, 2015) are some of the main areas to be investigated. Some highly ranked journals have issued special editions on the role of diversity and inclusion (Theodorakopoulos \& Budhwar, 2015). It is very important area to be studied by combining all these above mentioned constructs. Most of the studies related to diversity Managements are in the western context. Developing countries have already invested too much on research capabilities regarding human resource management. Still these countries need more attention on quality research about human resource management. 
Previous research exists related to human resource (HR) practices, organizational culture and job satisfaction of the employees. Most of the researchers have replicated existing studies conducted in developed countries with authenticated instruments. Some have tried to find out the impact of HR practices on employees' commitment and job satisfaction (Bowra, Sharif, Saeed, \& Niazi, 2012; Iqbal, Arif, \& Abbas, 2011; Javed, Rafiq, Ahmed, \& Khan, 2012; F. Khan, Yusoff, \& Khan, 2014), and some have focus on finding out the reasons of employees' turnover (Ashar, Ghafoor, Munir, \& Hafeez, 2013; Bowra et al., 2012; Nawab \& Bhatti, 2011). Further, in the similar context have performed studies in Pakistan (Bowra et al., 2012; Irfan, Mohsin, \& Yousaf, 2009; Shahzad, Bashir, \& Ramay, 2008; Shahzad, Sarmad, Abbas, \& Khan, 2011). However, the past literature reveals that very few researchers have tried to find out the impact of diversity in Pakistani organizations (Bashir \& Ramay, 2008; Idrees, Abbasi, \& Waqas, 2013; Qayyum, Sharif, Ahmad, \& Khan, 2012). To the best of our knowledge and ability, up to date, almost none of the researcher has done research work on relationship between diversity and human resource management and impact of the latest trends of inclusion and emotions in organizational studies.

\section{Literature review}

\subsection{Job Satisfaction in Divers Environment}

Due to increase in globalization, it is now important to sort out all better ways either in the shape of better working place or in the shape of an effective workforce to enhance job satisfaction among diverse work force. The modern research highlighted various issues related to job satisfaction in diverse workforce environment. Due to this there is now more demand for global managers who can effectively interlink cross culture environment within the organization.(Ivancevich \& Gilbert, 2000; Jackson, Joshi, \& Erhardt, 2003; Zoogah \& Abbey, 2010). The organizations become never effective unless and until the employees are not getting satisfaction from their jobs. An effective global manager can only manage the diverse individual in an organization by handling the cultural differences effectively.(Barakat, Lorenz, Ramsey, \& Cretoiu, 2015). This is the reason the global researchers are now giving more importance to the global managers who can manage challenges effectively and tactfully. What kind of characteristics must be available in those global managers which enable them to understand and balance the dynamics of distinct culture environment, appraise the differences, and behave appropriately in an unfamiliar setting.(Cappellen \& Janssens, 2005).In an organization, workforce profile is composed of workers group that shows the differences depending on demographic or other characteristics due to which diversity emerges. Previous research already highlighted the importance of the job satisfaction among employees and how this effect on organizational effectiveness. But due to globalization this issue again raised and need to tackle it with new ways in diverse environment.(A. G. Khan \& Hongyi, 2016)

It is fact that the Job satisfaction is getting more importance in modern globalization due to rapidly changes in the factors which are increasing or decreasing Job Satisfaction. Although there are huge literature and research work already done regarding how to enhance job satisfaction among the employees. But there is always need to research on those cotemporary factors which are effecting the job satisfaction. This study focusing on the increase of job satisfaction through human resource practices in diverse environment. Many research in view that inclusive human resource practices always enhance the job satisfaction among diverse employee. In the modern globalization due to rapid migrating of workforce all-over the world for better employment and for the quality product every organization are hosting different diverse workforce in their organization. Mostly due to lack of managerial expertise of the management the employees are getting demotivated. In this study it links some human resource practices with the job satisfaction. Many definitions of job satisfaction exist in the literature(Kabak, Şen, Göçer, Küçüksöylemez, \& Tuncer, 2014). Thus job satisfaction is a widely studied phenomenon. It can be the effect on employees mental, professional, social and personal life and all these effects altogether to the organization(de Lourdes Machado, Soares, Brites, Ferreira, \& Gouveia, 2011). Satisfaction is viewed, by some, as a predictor of positive attitudes at work, productivity, and, consequently, results for the organization. Employees who are more satisfied with their jobs absent, less likely to leave and more likely to be satisfied with their lives(Kirkman \& Shapiro, 2001). The consequences of job satisfaction are, therefore, individual and varied, covering personal and professional plans. Job satisfaction can hence be a source of health, as well as dissatisfaction can lead to damage to physical, mental and social health, leading to problems in the organization and in the work environment(Marqueze \& de Castro Moreno, 2005). Thus, job satisfaction is a widely studied phenomenon and this interest stems from the influence it can have on workers, affecting their physical and mental health, attitudes, professional and social behaviour, both with implications for individual's personal life and for organizations(Martinez \& Paraguay, 2003). 
By keeping the importance of job satisfaction and the contemporary factors which are effecting the job satisfaction this study focused on some human resource practices which can enhance the job satisfaction among employees if the organization want to manage diversity in an effective manner.

\subsection{Inclusive Human Resource Practices}

In today's competitive world every company wants to prosper and to have a competitive advantage through the use of best processes and high tech infrastructure. But who is going to implement and use all these processes and technologies; is the main area of concern. It's the human resource which is going to get best or worst out of all these processes and technologies.(Biswas, 2009; SamGnanakkan, 2010). It depends upon the good HR department to include the best employees 'and that department has the responsibility to design such HR policies and practices which can attract, train, retain, compensate and promote such human resources (Ananthram \& Chan, 2013; Hussain ${ }^{1} \&$ Ahmad, $^{2}$ 2012; Javed et al., 2012). There are a large number of HR practices being implemented in different organizations depending upon their size, type of industry and organizational culture etc. but most of the commonly used HR practices reported by many scholars which have experimental confirmation of solid association with workers execution reenrolment and choice, preparing, pay and administration, representative execution and assessment, advancement hones, complaint strategy, benefits program or social security etc(F. Khan et al., 2014; Syed, Bhatti, Michael, Shaikh, \& Shah, 2012; Teclemichael Tessema \& Soeters, 2006).HR practices have a very strong link with the organizational culture as reported by many scholars around the globe.(Abdul Ghafar Khan, 2016). The previous research most of the researchers focused on following main human resource practices while managing the diversity.

\subsubsection{Recruitment}

Recruitment is the main channel by which the organization chose the better candidate for the work. If this process is carried through proper professional way there is a less chance of grouping among the diverse employees or raising issues related to diverse background employees. How increase the job satisfaction in diverse environment through recruitment? The reputed and well organised organization always ensures the transparency in this process. For example the information about the job is always accessible to everyone no matter the recruitment is made within the organization or outside the organization. Secondly the organization policies must be reflect that the organization value only talent. Therefore the effective recruitment always help to decrease the absenteeism, turnover ratio and increase job involvement in diverse environment. The effective ways of recruitment always lead for an effective organization and similarly always lead for competitive advantages as well Chen Y-G 2012.

\subsubsection{Training and Development}

Training is very important from all aspect for the organization. Training is basically tailoring the skills, attitudes, behaviour and other employees existing knowledge according to the need of the organization. According to the researcher basically the training provide to all existing and new employees to build team work, develop more skills and re aligning the skills of the employees according to the need of the organization. As per the researcher that the employees training is also very important for organizational performance (Amin, Khairuzzaman Wan Ismail, Zaleha Abdul Rasid, \& Daverson Andrew Selemani, 2014).

\subsubsection{Performance Appraisal}

The researcher in view that in diverse workforce environment the most important thing is to be very fair in performance appraisal. So there are various ways one can adopted according to the situation. For example to update each and every one employees regarding the appraisal due dates, policies, criterial and the ways of judgments to their work. In the same way the fairness in the shape of time, duration, standers and description of the ways of appraisal. This is the most important factor which can influence badly in diverse background environment if not take properly. if you want to fair in your appraisal and introduce standers without judging the diverse background of the employees the result always going to be worse background of the divers. For example you are fix one slandered question among the different nature animals to climb on the tree, in this case fish will more suffer but cat will enjoy.

\subsubsection{Remuneration}

In other words rewards are the protection boundary to retain talented and experience employees. To the some extend employees ignore the importance of reward and compensation but when they feel that their experience and skills are exploited by rewarding less amount of money then employees start to search for other organizations and as a result 
The organization suffer from experience and talent employees on which organization already invest in term of training, development and providing other benefits (Amin et al., 2014).

By keeping the above literature tis study fix the following hypothesis

$\mathbf{H}_{\mathbf{1}}$ :Diversity Management in HR Practices has a positive relationship with job satisfaction.

$\mathbf{H}_{1 \mathbf{a}}$ :Diversity practices in recruitment function has positive relationship with job satisfaction.

$\mathbf{H 1}_{\mathbf{b}}$ : Diversity practices in training and development function has a positive relationship with job satisfaction.

$\mathbf{H}_{1 \mathbf{c}}$ : Diversity practices in performance appraisal function have a positive relationship with job satisfaction.

$\mathbf{H 1}_{\mathrm{d}}$ : Diversity practices in remuneration function has a positive relationship with job Satisfaction

\subsection{Mediating Role of Inclusion}

In the start of research on diversity topic, it was mainly related to the problems associated with the diversity and absence of any concrete steps to handle issues related to it.(Barak, 1999; Stoermer, Hildisch, Froese, Tung, \& klarsfeld, 2016). Even for a longer period of time, it was being researched to find out the types and variations in the diversity literature. But for the last few years, researchers have started focusing on the management of diversity related issues and one of the key construct under study related to it is "inclusion"(Findler, Wind, \& Barak, 2007; Shore et al., 2010). Identification create a great impact toward in-group and out-group perceptions.(Stets \& Burke, 2000). Identification with social categories, such as those in the diversity literature, is "based on symbolic attachment to the group as a whole". Social identification makes motivate people to attach with each other for common interests through group effort. In addition to this social component, identity also contains a personal element that involves defining oneself as an individual.(Brewer, 2007). Therefore, social identities contribute to less individuation as people incorporate group aspects into their self-concepts. He also explains strains related with "human needs for justification and similarity to others (on the one hand) and a countervailing need for uniqueness and individuation (on the other)." Brewer claimed that persons seek to balance these two needs through an optimal level of inclusion through the groups which they adopted for their common interest. To fulfil a fundamental human need for belongingness (defined as the need to form and maintain strong, stable interpersonal relationships; (Leary, Schreindorfer, \& Haupt, 1995), The individuals seeks social identification through the groups which they belong by proving themselves that they are the part of this group, and the sense of connection with others that it creates, prevents the isolation that may happen if one becomes highly individuated.(Pickett, Silver, \& Brewer, 2002). Being an accepted member of a group give feeling of belongingness, strength and a feeling of achievement which is a result of the psychological thinking of loyalty, cooperation and trust upon each other.(Linares, 2015; Shore et al., 2010; Trytten, Pan, \& Foor, 2015). It has been stated that if any organization wants to get maximum output of its diversified workforce, its policies will enhance a culture of belongingness which will increase the job satisfaction level of the employees:

$\mathbf{H}_{2}$ :Diversity Management in HR Practices has a positive relationship with Inclusion.

$\mathbf{H}_{3}$ : Inclusion has a positive relation with Job Satisfaction

$\mathbf{H}_{4}$ : Inclusion has act as a mediator for the relationship between Diversity oriented Human

Resource Practices and Job Satisfaction

\subsection{Theoretical Discussion}

\subsubsection{Perceived Organizational Support (Richard A. Posthuma et al.)}

Perceived Organizational Support is the employee's global beliefs concerning the extent to which the organization values his or her contributions and cares about his or her well-being ${ }^{[14]}$. POS reflects two focal areas of perceptions. The first is the perceived value given to the one's contribution. The second is the perceived caring about one's wellbeing of the organization. It is a reciprocal phenomenon in which it is believed that an employee will try to return more than what the individual has received from the organization. It is one of very key studied area in the commitment of employees with the organization that describes that employee first looks for the commitment of the organization to the employees and then they responds accordingly. Organizations for employees are not only the source of physical items like salary and other monetary benefits but also they hope for respect and care which fulfil their needs of approval, esteem and affiliation. A positive evaluation by the organization and top management gives an indication that anyone who put his/her best will be rewarded accordingly without any discrimination. As three of the main antecedents of POS are supervisor support, fairness and organizational reward and job condition. All these will leads to a sense of inclusion and feeling of social support in the eyes of an employee which will increase his/her job satisfaction and commitment to the organization. 


\subsubsection{Equity Theory}

This theory mainly focusing on the equal distribution of the resources. This theory further highlighted that the resource must be distributed according to goal of achieving targets.

According to (Adams, 1963)people always comparing their efforts with those facilities which they are receiving as a rewards of their efforts and what the other treated in the same efforts(Carrell \& Dittrich, 1978).People mostly measure the equity by value of their input (Their efforts) and what they are receiving (outputs) as a result of their inputs and comparing the situation with similar group individual. In the context of management science the Equity theory has a great importance. The reason behind is that it directly hit the motivational level of the employees working within the organization. This theory aims to maintain a balance between individual inputs and output at work place.(Adams, 1963). Many researchers explain the term input in equity theory. Input refers the time, expertise, experience, skills and what they have to perform particular task in effective manner. And in the same way outcomes includes, monetary benefits, rewards extrinsic and extrinsic and all those which satisfy employee or motivate them to continue their efforts (inputs). In the organization if employees feel inequity then it effect on motivational level of employees while performing particular task (Carrell \& Dittrich, 1978). This theory exactly apply in the organization. If the them of this theory is properly applied within the organization it enhance the belongingness of the employees with the organization. Specially where the diverse people are working. In another words this theory take an important role while managing the diverse people. The reason behind is that the minority and majority in both cases quickly hit inequality practices while dealing with diverse people. If within the organization individual feels that they are not equally treated then its consequence appear in shape of less productivity, grouping among the diverse people and non-productive issues and conflicts.

In general settings if an individual or a group of people feel that in comparison to individuals of some other group they are getting less pay although they have same qualification, experience, job position and aload of work, then it will create a sense of disappointment and anger within those individuals or groups. Most of the literature shows that female workers are under paid even in most of the fortune 500 companies. Similarly some ethnic groups or immigrants in some countries are used to face such situation. Companies do not attach their diversity management practices with compensation practice of HR that results in such situation which according to equity theory will result in anger and distrust.

While if employees of different backgrounds and groups feel that they being treated equally by their superiors and organization as a whole it will increase their feeling of inclusion and sense of belongingness and social support. All this will leads to commitment with the organization and job satisfaction level of employees will be higher that will ultimately improve the organizational performance.

This study has proposed based upon above literature that organizational culture variables of inclusion and social support will act as moderators to increase the employee's commitment if the organization applies HR practices by strategically incorporating diversity management through them. It's the application of POS and equity theory that will improve the confidence of employees in organization and they will feel more included and enjoy the social support they will be feeling through that.

\section{Conceptual Model}

After heavily studied the existing literatures we have designed the conceptual model for this study. The conceptual model of this study is presented in figure 1 . The conceptual model revealed that inclusion directly leads job satisfaction. This concept has robust association with equity theory. This theory focuses on determining whether the distribution of resources is fair to all relational partners. According to (Adams, 1963) individuals compare their job inputs and outcomes with those of others and then respond to eliminate any inequities. There studies finding reveals that inclusion have significance impact on job satisfaction. Similarly, the relationship between HR practices and employees' job satisfaction has been studied by many researcher, such as(Javed et al., 2012; Stevens, Oddou, Furuya, Bird, \& Mendenhall, 2006; Tooksoon, 2011). Moreover, the role of diversity with respect to HR practices has positive and direct impact on job satisfaction and studied by various researcher, for example,(Böhm et al., 2014; Cox \& Beale, 1997; Denice \& Lawrence, 1994; Metcalte et al., 2007). 


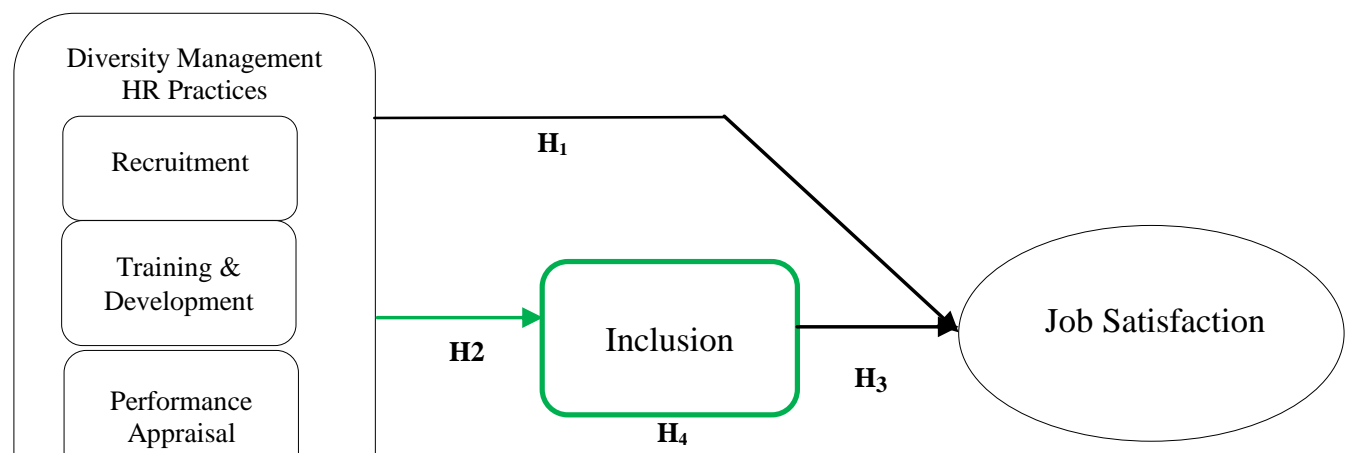

Figure 1.Conceptual Model for the study

After going through variousliteratures review specially those which specially focused the diversity management in the various organizations. We have developed the following hypothesis based upon above discussion. Moreover, our hypothesis included all those literatures which partially apply the hypothesis in their research work in the different situation.

$\mathbf{H}_{\mathbf{1}}$ : Diversity Management in Human Resource Practices have a positive relationship with Job Satisfaction.

$\mathbf{H}_{2}$ : Diversity Management in Human Resource Practices have a positive relationship with Inclusion

$\mathbf{H}_{3}$ : Inclusion has a positive relationship with Job Satisfaction.

$\mathbf{H}_{4}$ : Inclusion act as mediator for the relationship between Diversity Management Human Resource Practices and Job Satisfaction.

\section{Research Methodology}

This study was based on casual. A survey was conducted by using the instrument of questionnaire to check the relationship among all set variables. Pilot study was conducted by collection data from 14 universities out of which seven were public and remaining seven were private universities. A 7 point Likert type scale is used to measure all the items as they were originally used in their respective research studies. Scale was $1=$ Strongly Disagree, $2=$ Disagree, 3 $=$ Slightly Disagree, $4=$ Neutral, $5=$ Slightly Agree, $6=$ Agree, $7=$ Strongly Agree. For any research under positivistic approach, the researcher needs to collect data from a sample oftheintended population. The population forthecurrent study is consists of all the universities of Pakistan.

As this study is based on primary data. The data was collected from 5 randomly selected universities of Pakistan. The data was taken from HR department personal and faculty members of the concerned universities. A statistical sampling method named cluster sampling was adopted as there are two main clusters of universities in Pakistan. The public sector and private sector universities. As a model in this study has 6 constructs and structural equation modelling is needed to apply, the sample size between 150 and 200 is considered as the best sample size((Hair, Black, Babin, Anderson, \& Tatham, 2006). The data was collected from 200 respondents of randomly selected universities. A wellstructured questionnaire was used based on all concerned constructs and was tested. After all the questionnaire was finalized.

\section{Data Analysis}

The collected data was analysed through SPSS. For this purpose the following tests were run:

1. Reliability test to check the validity of the questionnaire

2. Other test primarily important to test conceptual Model. 


\subsection{Demographic Information}

\subsubsection{Ethnicity}

\begin{tabular}{lcccc}
\hline & Frequency & Percent & Valid Percent & Cumulative Percent \\
\hline Punjab & 111 & 56.1 & 56.1 & 56.1 \\
Sindh & 14 & 7.1 & 7.1 & 63.1 \\
KPK & 43 & 21.7 & 21.7 & 84.8 \\
Baluchistan & 1 & .5 & .5 & 85.4 \\
Gilgit Baltistan & 15 & 7.6 & 7.6 & 92.9 \\
AJ\&K & 14 & 7.1 & 7.1 & 100.0 \\
& Total & 198 & 100.0 & 100.0 \\
\hline
\end{tabular}

\subsubsection{Gender}

\begin{tabular}{lccccc}
\hline Male & & 119 & 60.1 & 60.1 & 60.1 \\
Female & & 79 & 39.9 & 39.9 & 100.0 \\
& Total & 198 & 100.0 & 100.0 & \\
\hline
\end{tabular}

5.1.3. Age

\begin{tabular}{lccccc}
\hline $25-35$ Years & 132 & 66.7 & 66.7 & 66.7 & \\
$36-45$ Years & 55 & 27.8 & 27.8 & 94.4 & 98.0 \\
$46-55$ & 7 & 3.5 & 3.5 & 100.0 \\
$56-65$ & 4 & 2.0 & 2.0 & 100.0 & \\
& Total & 198 & 100.0 & & \\
\end{tabular}

\subsubsection{Marital Status}

\begin{tabular}{lccccc}
\hline Married & & 117 & 59.1 & 59.1 & 59.1 \\
Unmarried & & 81 & 40.9 & 40.9 & 100.0 \\
& Total & 198 & 100.0 & 100.0 & \\
\hline
\end{tabular}

5.1.5. Educational Status

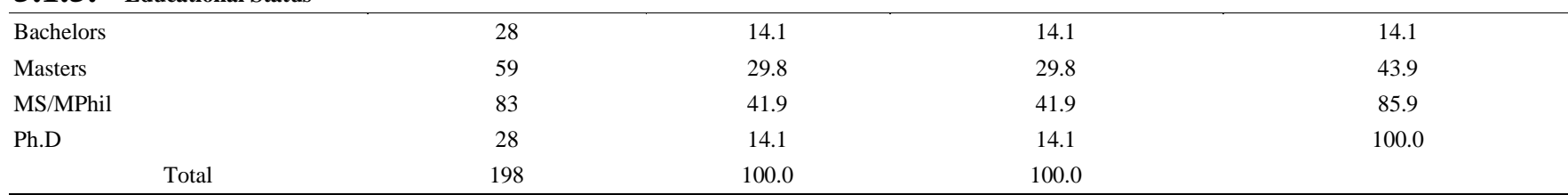

5.1.6. Departmental Status

\begin{tabular}{rcccc}
\hline Faculty & 115 & 58.1 & 58.1 & 58.1 \\
Administrative Staff & 83 & 41.9 & 41.9 & 100.0 \\
Total & 198 & 100.0 & 100.0 &
\end{tabular}

To obtain descriptive statistics for categorical variable use of frequencies. The above table shows the domicile of province .111 Punjab had 56.1\%, 14 Sindh had 7.1\%,43kpk had 21.7\%,1Balochistan 1\%,15Gilgit Baltistan 7.6\%and 14 Aj\&k 7.1\% in the total of 198 respondents. To obtain descriptive statistics for categorical variable use frequencies. From the output shown above that there are males in the range of 119 (60.1 percent) and females in the range of 76 (39.9 percent) in the sample containing 198 respondents. The output shows that 132 employees age group (25_35) is $66.7 \%, 55$ employees age group (36_45) is $27.8 \%$ and 7 employees age group (46_55) is 3.5,4 employees age group (56_65) is $2.0 \%$, in the sample containing 198 respondents.In the above table 117 are married and their percentage is $59.1 \%$ and 81 are unmarried and their percentage $40.9 \%$ in total 198 respondents.

In the above table there were 28 bachelor degree holders and their qualification percentage is $14.1,59$ master degree holders and their qualification percentage is $29.8 \%, 83$ wereMs/Mphilland their percentage is 41.9 and 28 were PHD degree holders and their percentage is $14.1 \%$ in the total of 198 respondents. In the above table 115 faculty percentage is $58.1 \%, 83$ were administrative staff and percentage is 41.9 among 198 respondents. 


\subsection{Reliability Analysis}

\begin{tabular}{|c|c|c|c|}
\hline Variable & Items & Cronl & \\
\hline 1 & Recruitment & 6 & .904 \\
\hline 2 & Training and development & 6 & .856 \\
\hline 3 & Performance Appraisal & 5 & .868 \\
\hline 4 & Remuneration and Function & 5 & .881 \\
\hline 5 & Inclusion & 14 & .916 \\
\hline 6 & Job satisfaction & 3 & .785 \\
\hline
\end{tabular}

(Carmines \& Zeller, 1979) mentioned that the reliability test of the research instrument are always explain that to what extent the instrument produced the same results on test . (Creswell, Plano Clark, Gutmann, \& Hanson, 2003) stated, "Reliability means that scores from an instrument are stable and consistent". (Leech \& Onwuegbuzie, 2009) findings showed that internal consistency was a popular method used to estimate reliability and that the Cronbach alpha coefficient was an index used for reliability estimation. (Cronbach, 1951)mentioned the standards that if the alpha coefficient $(<0.50)$, then it mean the items are not associate with the variable; when $.70<$ alpha $<.90$, then it mean the items of the variables properly explain the variable. If the result is showed $.90<$ alpha $<1$, then the result will show the strong association and considered to be excellent. Most researchers believed the reliability of the instrument must be the alpha coefficient more than .70 . The researcher utilized the Cronbach alpha to calculate the reliability of all factors.

The above table indicates the total items for each variable and as per above result while running test to check reliability for each, we received following results. Recruitment had 6 item their reliability was .940, Training and Development had 6 item was .856. Performance Appraisal was 5 item .868 and Remuneration has 5 item .881. Inclusion has 14 item their reliability value is 0.916 . The job satisfaction has 3 items their reliability value was .785 . So all the items are statistically significant because their reliability was above $90 \%$.

\subsection{Descriptive Statistics}

\begin{tabular}{lccrrr}
\hline & N & Minimum & Maximum & Mean & Std. Deviation \\
\hline Recruitment & 198 & 1 & 7 & 3.9596 & 1.46053 \\
Training \&Development & 198 & 1 & 7 & 4.00 & 1.251 \\
Performance Appraisal & 198 & 1 & 7 & 4.03 & 1.389 \\
Remuneration & 198 & 1 & 7 & 4.0283 & 1.43644 \\
Inclusion & 198 & 1 & 7 & 4.1721 & 1.12814 \\
Job satisfaction & 198 & 1 & 7 & 4.2694 & 1.12318 \\
Valid N (list wise) & 198 & & & & \\
\hline
\end{tabular}

The descriptive statistics of variables generated in the above table shows the values and standard deviation. The mean of variables indicate the relative position of the majority of the responses. The mean values of variables recruitment, Training and development, performance Appraisal, remuneration, inclusion and job satisfaction means 3.95,4.00,4.03,4.02,4.17,4.26 and standard deviation values are 1.46,1.25,1.38,1.44,1.12,1.123 with sample size of 198 show that majority of the responses on these fall within 7 (strongly agree). 


\subsection{Correlation}

\section{Correlations}

\begin{tabular}{|c|c|c|c|c|c|c|c|}
\hline & & DPR & DPTD & DPPA & DPR & INC & JB \\
\hline & Pearson Correlation & $.624^{* *}$ & $.591^{* *}$ & $.604^{* *}$ & $.620^{* *}$ & $.673^{* *}$ & 1 \\
\hline \multirow{2}{*}{ JS } & Sig. (2-tailed) & .000 & .000 & .000 & .000 & .000 & \\
\hline & $\mathrm{N}$ & 198 & 198 & 198 & 198 & 198 & 198 \\
\hline
\end{tabular}

*DPR- Diversity Practices in Recruitment

*DPTD- Diversity Practices in Training and Development

*DPPA- Diversity Practices in Performance Appraisal

*DPR- Diversity Practices in Remuneration

*INC- Inclusion

*JB- Job Satisfaction

This test was run to check the potential and direction of the relationship between variables of the study. The purpose of this text is to examine to check the relationship of all variables which is considered to be independent with our dependent variable Job satisfaction.

The above table shows that all the variables of the study had positive and significant correlation with one another. Recruitment impact on job satisfaction is $(\mathrm{r}=0.624 * * *)$ i.e $(0.01)$ is highly significant. The impact of Training Development on job satisfaction is $(\mathrm{r}=.591 * * *)$ i.e $(\mathrm{p}<0.01)$ is highly significant. The impact of performance Appraisal impact on Job satisfaction is $(\mathrm{r}=.604 * * *)$ i.e is highly significant. The impact of Remuneration on job satisfaction is $\left(\mathrm{r}=.620^{* * *}\right)$ i.e highly significant. The impact of inclusion on job satisfaction $(\mathrm{r}=.673 * * *)$ i.e is highly significant

\subsection{Regression Analysis}

Table : Regression Analysis of Diversity Management on job satisfaction, mediating role of Inclusion

\begin{tabular}{|c|c|c|c|c|}
\hline & $R$ & $R^{2}$ & $R^{2}$ Change & Beta \\
\hline $\begin{array}{l}\text { Analysis one: } \\
\text { Diversity Management on Job Satisfaction }\end{array}$ & $0.6750 * * *$ & 0.4556 & & $0.6058 * * *$ \\
\hline $\begin{array}{l}\text { Analysis Two: } \\
\text { Diversity Management on Inclusion }\end{array}$ & $0.8529 * * *$ & 0.7275 & & $0.7685 * * *$ \\
\hline $\begin{array}{l}\text { Analysis Three: } \\
\text { Step one: Inclusion on Job Satisfaction }\end{array}$ & $0.673 * *$ & 0.452 & & $0.3541 * *$ \\
\hline $\begin{array}{l}\text { Step Two: Diversity Management \& job Satisfaction on } \\
\text { Inclusion }\end{array}$ & $0.7000^{* * *}$ & 0.4900 & 0.4849 & $0.3336 * * *$ \\
\hline
\end{tabular}

\section{$* \mathbf{p}<.05 ; * * \mathbf{p}<.01 ; * * * \mathbf{p}<.001$,}

As shown in table, the diversity management HR practices has significantly affects the employees job satisfaction. As per statistical analysis one, it is confirmed that Diversity management and job satisfaction had a significant relationship (Beta=0.6058, $\mathrm{p}<.01)$. In step 2 Diversity Management and inclusion had a significant relationship (Beta=0.7685, $\mathrm{p}<.01)$. In step 3, inclusion impact on job satisfaction had (Beta $=0.3336, \mathrm{p}<.01)$ and coefficient regression of Diversity management and job satisfaction is $0.7000, \mathrm{p}<.01)$. This demonstrated inclusion acts as a mediation relationship between Diversity management and job satisfaction.

We have found multiple elements of our conceptual model influences the job satisfaction, whereas Inclusion strengthens the relationship between Delivery Management HR Practices on Job satisfaction

\section{Discussion of Findings}

The above findings indicates that the hypothesis we have fixed have a positive relations with Job Satisfaction. The organizations who are engaging with inclusive oriented human resource practices, they can effectively manage the diverse workforce 
Though the diversity management is the use of effective HR practices and policies and it can develop main competitive advantage for institutions. Moreover, institutions need to provide necessary skills to their staff. Furthermore, some of the social issues such as integration, exclusion, inclusion, and social support are there to be tackled attheorganizational level. So that institutional policies required for the better hiring of staff with the better skills. We need to know the positive aspects of diversity and this will not be gotten just by observing diversity attheworkplace. However, if not managed well, this might create the environment of increased turnover(Coşar, Guner, \& Tybout, 2016), damage morale(Kube, Maréchal, \& Puppe, 2013), and cause some communication issues and problems.(Gregory \& Bryan, 2015; Heath \&Bryant, 2013; Morrison, 2014; Williams \& Adams, 2013; Wright, 2016). Thus, the true benefits can be got by effective management diversity in HR practices at the time of recruitment(Richard, Roh, \& Pieper, 2013; Stone, 2013; Stredwick, 2013)

The first element of diversity management HR practices explained the recruitment. Hence, the finding of our research investigated and found diversity as a prominent factor in recruitment. In the field of diversity in HR, various studies have explored that employees in Asian countries are lacking in skills in future. It is so because we might see the greater number of migrants in the workforce (Frank, Liebman, Ryder, Weir, \& Arcury, 2013; Panikkar, Woodin, Brugge, Hyatt, \& Gute, 2014; Reitz, 2013)The recruitment is a significant factor in the field of HR. thus; this field is considered as the main gate for employees at the time of entry into the institutions. In addition, for the purpose of growth, effectiveness, and efficiency in HR practices, there is a change in the approach to cultural diversity with the better skills. In this is strongly required in the current age. In order to attract a bigger number of staff, job advertisement can be posted in ethnic magazines and newspapers. Thus, the recruitment quality can be improved by hiring staff from different ethnic and multiple experience backgrounds in the process of recruitment. Obviously, this would enable the organization to produce better performance.

Hence, we observed that institutions could enjoy the triumph while recruiting new staff with gaining access to multiple fields of knowledge and then understanding of employees with diverse skills.(Gabriel, Gabriel, \& Nwaeke, 2015; Lolli, 2013). Nevertheless, to get the goal of having skilled force, institutions must focus on diversity not only in recruitment but other processes of HR practices in management. Furthermore, we need to see diversity not a legal obligation but an advantage for organizations. Our next element of diversity management in HR practices was training and development and its growing importance.(Al-Shemmeri \& Naylor, 2016; Daniel \& Gabriela, 2013; James \& Lucky, 2015). Hence, the findings of our study investigated that discussing the training and development in diversity management will bring better results for educational institution. Henceforth, training and development is the necessary factor to achieve the desired result. A study elucidated that there is no such progression policies and career planning for ethnic diverse employees. However, these are mainly employed in production activities. Our data explored that educational institutions in Pakistan are not focusing on diverse staff in such a way that competitiveness, efficiency, and effectiveness could be achieved. Nonetheless, this reflects the significance of effectiveness of diversity practices.

Hence, our findings explored the there is a dire need of diversity practices in performance appraisal. Only managing diversity is not the ultimate goal of our study. But, to improve the performance in the area to develop more involvement and achieve organizational commitment and job satisfaction. Even though, an employee from other organizations would feel that they should have joined such organizations.

Hence, institutions are required to evaluate inequality because this can create negative feelings in the staff. Further, the top management needs to pay more attention during the performance appraisal of diversity. And top management should be the directly part of panel of performance appraisal so that this will improve the perception of a fair system in the entre process. Similarly, the integration in policies of performance appraisal will pay back as the better commitment and job satisfaction for the performance of the organization.

\section{Conclusion}

Academic institutions are the knowledge intensive organizations in every country. This institution has a great role to bring about positive changes in the minds of people and lead them towards positive direction. And the second main role of this knowledge intensive organization is to make them more skilful and productive for the country. Due to modern globalization, the diversity has becomea more challenging factor in every organization. By keeping the importance of higher education contribution to the national development and its very important role in various other development organizations to make more creative and innovative oriented then it is important to make the knowledge intensive organizations more effective. 
This is the reason academicals staff needs more attention to look into their matters because their job satisfaction and motivation play an important role and contribute to positive consequences and improve the quality of the institution and learning.(de Lourdes Machado et al., 2011). This is the reason that in the organizations where employees are treated on the basis of merit and without any discrimination, the employees always show a strong commitment to the organization, which also leads to job satisfaction.

This is the era of participate management, self-mentoring and self-motivated and inclusive style of management and leadership. No doubt today all organizations including academics institutions facing the challenges of outcomes of globalization and support and inclusion from cross border economies. So in this scenario, the management of diversity is more important than ever before. Especially the developing countries facing challenge very critically. Pakistan is one of the developing countries and consists of various ethnicity groups and especially due to political instability facing serious challenges in shape of terrorism and sectarian clashes among various religious sects. This is the reason our country needs more awareness about diversity and inclusion as compared to other countries.

\section{Limitations of the Study}

(1) Limited literature review available regarding diversity management various dimensions.

There was no proper research conducted regarding diversity management in our region. Most of the literature is available based on western research.

(2) Methodology

Due to the current scenario in our country, people are hesitating to share information. The reason behind is the continuous uncertainty, lack of research activities and unaware of research base knowledge. Sometime the respondents hide or try to avoid from sharing information.

(3) Survey to collect the data.

In this Study, the questionnaire was distributed among the employees ten to fifteen employees of sixteen universities in capital. Due to time and budget constraints a cross sectional study is performed which sometime limits the authenticity of the results or proposed solutions.

There are a lot of communication barriers and there is no infrastructure to access far-flung areas. It needs ahavey budget to access the remote areas. Due to budget constrain this study could not able to access to that respondent who is living far than capital. The future research can be carried out by eliminating the above limitations.

\section{References}

Abdul Ghafar Khan, X. H. (2016). Literature in Nutshell regarding Global Human Resource Management Challenges (HRM)- Literature Review. IOSR Journal of Business and Management (IOSR-JBM), 18(Issue 2), 10-16.

Adams, J. S. (1963). Towards an understanding of inequity. The Journal of Abnormal and Social Psychology, 67(5), 422.

Al-Shemmeri, T., \& Naylor, L. (2016). Energy saving in UK FE colleges: The relative importance of the socioeconomic groups and environmental attitudes of employees. Renewable and Sustainable Energy Reviews.

Amin, M., Khairuzzaman Wan Ismail, W., Zaleha Abdul Rasid, S., \& Daverson Andrew Selemani, R. (2014). The impact of human resource management practices on performance: Evidence from a Public University. The TQM Journal, 26(2), 125-142.

Ananthram, S., \& Chan, C. (2013). Challenges and strategies for global human resource executives: Perspectives from Canada and the United States. European Management Journal, 31(3), 223-233.

Ashar, M., Ghafoor, M., Munir, E., \& Hafeez, S. (2013). The impact of perceptions of training on employee commitment and turnover intention: Evidence from Pakistan. International journal of human resource studies, $3(1), 74$.

Ashikali, T., \& Groeneveld, S. (2015). Diversity management for all? An empirical analysis of diversity management outcomes across groups. Personnel Review, 44(5), 757-780.

Ayoko, O. B., \& Konrad, A. M. (2012). Leaders' transformational, conflict, and emotion management behaviors in culturally diverse workgroups. Equality, diversity and inclusion: An international journal, 31(8), 694-724.

Barak, M. E. M. (1999). Beyond affirmative action: Toward a model of diversity and organizational inclusion. Administration in Social Work, 23(3-4), 47-68.

Barakat, L. L., Lorenz, M. P., Ramsey, J. R., \& Cretoiu, S. L. (2015). Global managers: An analysis of the impact of cultural intelligence on job satisfaction and performance. International Journal of Emerging Markets, 10(4), 781-800. 
Bashir, S., \& Ramay, M. I. (2008). Determinants of organizational commitment: a study of information technology professionals in Pakistan. Journal of Behavioral and Applied Management, 9(2), 226.

Biswas, S. (2009). HR practices as a mediator between organizational culture and transformational leadership: implications for employee performance. Psychological Studies, 54(2), 114-123.

Boccagni, P. (2015). (Super) diversity and the migration-social work nexus: a new lens on the field of access and inclusion? Ethnic and Racial Studies, 38(4), 608-620.

Böhm, S. A., Kunze, F., \& Bruch, H. (2014). Spotlight on Age-Diversity Climate: The Impact of Age-Inclusive HR Practices on Firm-Level Outcomes. Personnel Psychology, 67(3), 667-704.

Bowra, Z. A., Sharif, B., Saeed, A., \& Niazi, M. K. (2012). Impact of human resource practices on employee perceived performance in banking sector of Pakistan. African Journal of Business Management, 6(1), 323.

Brewer, M. B. (2007). The importance of being we: human nature and intergroup relations. American Psychologist, 62(8), 728.

Cappellen, T., \& Janssens, M. (2005). Career paths of global managers: Towards future research. Journal of World Business, 40(4), 348-360.

Carmines, E. G., \& Zeller, R. A. (1979). Reliability and validity assessment (Vol. 17): Sage publications.

Carrell, M. R., \& Dittrich, J. E. (1978). Equity theory: The recent literature, methodological considerations, and new directions. Academy of management review, 3(2), 202-210.

Chiao, J. Y. (2015). Current emotion research in cultural neuroscience. Emotion Review, 1754073914546389.

Coşar, A. K., Guner, N., \& Tybout, J. (2016). Firm dynamics, job turnover, and wage distributions in an open economy. The American Economic Review, 106(3), 625-663.

Cox, T., \& Beale, R. L. (1997). Developing competency to manage diversity: Readings, cases \& activities: BerrettKoehler Publishers.

Creswell, J. W., Plano Clark, V. L., Gutmann, M. L., \& Hanson, W. E. (2003). Advanced mixed methods research designs. Handbook of mixed methods in social and behavioral research, 209, 240.

Cronbach, L. J. (1951). Coefficient alpha and the internal structure of tests. psychometrika, 16(3), 297-334.

Daniel, B., \& Gabriela, B. (2013). Analysis of Employee's Motivation in Health InstitutionsAbstract: The article presents a survey of employee motivation in a health institution based on ERG theory. The questionnaire was applied during 1.09. 2013-1.10. 2013 to all 68 employees of the institution. The existential needs include six elements: salary, salary increases, benefits, endowment, area accessibility and clarity of the tasks. The 8 elements that describe the relational needs are: communication between employees, colleague's devotion, number of friends, trust between employees, professional relationship with head management, free time, flexibility of management decision and team work. The category of growth needs includes: importance of personal works, satisfaction, the power to take decisions, praise and appreciation during the last day, performance evaluation and assessment of progress, the possibility of training and advancement. Ovidius University Annals, Economic Sciences Series, 13(2), 375-378.

de Lourdes Machado, M., Soares, V. M., Brites, R., Ferreira, J. B., \& Gouveia, O. M. R. (2011). A look to academics job satisfaction and motivation in Portuguese higher education institutions. Procedia-Social and Behavioral Sciences, 29, 1715-1724.

Denice, W., \& Lawrence, W. (1994). Linking operation mode diversity and IHRM. International Journal of Human Resource Management, 5(4), 911-926.

Downey, S. N., Werff, L., Thomas, K. M., \& Plaut, V. C. (2015). The role of diversity practices and inclusion in promoting trust and employee engagement. Journal of Applied Social Psychology, 45(1), 35-44.

Findler, L., Wind, L. H., \& Barak, M. E. M. (2007). The challenge of workforce management in a global society: Modeling the relationship between diversity, inclusion, organizational culture, and employee well-being, job satisfaction and organizational commitment. Administration in Social Work, 31(3), 63-94.

Frank, A. L., Liebman, A. K., Ryder, B., Weir, M., \& Arcury, T. A. (2013). Health care access and health care workforce for immigrant workers in the agriculture, forestry, and fisheries sector in the southeastern US. American journal of industrial medicine, 56(8), 960-974.

Gabriel, J., Gabriel, L., \& Nwaeke, L. (2015). Reappraising Human Resource Management Practices as Predictor of Employees' Performance in the Nigerian Banking Industry: Current Evidence. nature, 7(24).

Gregory, J., \& Bryan, K. (2015). Speech and language therapy intervention with a group of persistent and prolific young offenders in a non-custodial setting with previously undiagnosed speech, language and communication difficulties. International Journal of Language \& Communication Disorders, 1-14. 
Guillaume, Y. R., Dawson, J. F., Woods, S. A., Sacramento, C. A., \& West, M. A. (2013). Getting diversity at work to work: What we know and what we still don't know. Journal of occupational and organizational psychology, 86(2), 123-141.

Hair, J. F., Black, W. C., Babin, B. J., Anderson, R. E., \& Tatham, R. L. (2006). Multivariate data analysis (Vol. 6): Pearson Prentice Hall Upper Saddle River, NJ.

Heath, R. L., \& Bryant, J. (2013). Human communication theory and research: Concepts, contexts, and challenges: Routledge.

Hussain1, M., \& Ahmad, M. (2012). Mostly Discussed Research areas in Human Resource Management (HRM)-A Literature Review. Management, 2(3), 10-17.

Idrees, R. N., Abbasi, A. S., \& Waqas, M. (2013). Systematic Review of Literature on Workforce Diversity in Pakistan. Middle-East Journal of Scientific Research, 17(6), 780-790.

Iqbal, M. Z., Arif, M. I., \& Abbas, F. (2011). HRM practices in public and private universities of Pakistan: A comparative study. International Education Studies, 4(4), 215.

Irfan, S. M., Mohsin, M., \& Yousaf, I. (2009). Achieving service quality through its valuable human resources: An empirical study of banking sector of pakistan. World Applied Sciences Journal, 7(10), 1222-1230.

Ivancevich, J. M., \& Gilbert, J. A. (2000). Diversity management time for a new approach. Public personnel management, 29(1), 75-92.

Jackson, S. E., Joshi, A., \& Erhardt, N. L. (2003). Recent research on team and organizational diversity: SWOT analysis and implications. Journal of management, 29(6), 801-830.

James, O., \& Lucky, O. (2015). The Impact of Training on Employees Job Erformance: An Empirical Study of Selected Organizations in Warri, Delta State. Journal of Policy and Development Studies, 9, 111-125.

Javed, M., Rafiq, M., Ahmed, M., \& Khan, M. (2012). Impact of HR practices on employee job satisfaction in public sector organizations of Pakistan. Interdisciplinary Journal of Contemporary Research in Business, 4(1), 348.

Kabak, K. E., Şen, A., Göçer, K., Küçüksöylemez, S., \& Tuncer, G. (2014). Strategies for Employee Job Satisfaction: A Case of Service Sector. Procedia-Social and Behavioral Sciences, 150, 1167-1176.

Khan, A. G. (2015). Cross-Border Investment -Culture is challenging factor for the HR Management to the Chinese Enterprises. Paper presented at the 12th International conference on innovation and Management.

Khan, A. G., \& Hongyi, X. (2016). Roots of Diversity in the Academics Institutions: How HR Manager Can Encounter the Challenges of Workplace Diversity. INNOVATION AND MANAGEMENT.

Khan, F., Yusoff, R. M., \& Khan, A. (2014). Effect of human resource practices on job satisfaction in Pakistan. Sains Humanika, 1(1).

Kirkman, B. L., \& Shapiro, D. L. (2001). The impact of cultural values on job satisfaction and organizational commitment in self-managing work teams: The mediating role of employee resistance. Academy of Management journal, 44(3), 557-569.

Kube, S., Maréchal, M. A., \& Puppe, C. (2013). Do wage cuts damage work morale? Evidence from a natural field experiment. Journal of the European Economic Association, 11(4), 853-870.

Leary, M. R., Schreindorfer, L. S., \& Haupt, A. L. (1995). The role of low self-esteem in emotional and behavioral problems: Why is low self-esteem dysfunctional? Journal of Social and Clinical Psychology, 14(3), 297-314.

Leech, N. L., \& Onwuegbuzie, A. J. (2009). A typology of mixed methods research designs. Quality \& quantity, 43(2), 265-275.

Linares, C. (2015). A Phenomenological Approach to First-Generation Latino Immigrants' Experiences of Cultural Diversity and Inclusion Initiatives in the Workplace. SULLIVAN UNIVERSITY.

Lolli, J. C. (2013). Interpersonal communication skills and the young hospitality leader: Are they prepared? International Journal of Hospitality Management, 32, 295-298.

Marqueze, E. C., \& de Castro Moreno, C. R. (2005). Satisfação no trabalho-uma breve revisão1 Job satisfaction-a short review. Política Editorial, 5409(112), 69-79.

Martinez, M. C., \& Paraguay, A. I. B. B. (2003). Satisfação e saúde no trabalho: aspectos conceituais e metodológicos. Cadernos de psicologia social do trabalho, 6, 59-78.

Metcalte, B. D., of Hull Business School, U., Fielden, S., Business School, M., of Manchester, U. U., Barbosa, Í., \& Cabral-Cardoso, C. (2007). Managing diversity in academic organizations: a challenge to organizational culture. Women in Management Review, 22(4), 274-288.

Morrison, E. W. (2014). Employee voice and silence. Annu. Rev. Organ. Psychol. Organ. Behav., 1(1), 173-197. 
Nawab, S., \& Bhatti, K. K. (2011). Influence of employee compensation on organizational commitment and job satisfaction: A case study of educational sector of Pakistan. International Journal of Business and Social Science, 2(8).

Panikkar, B., Woodin, M. A., Brugge, D., Hyatt, R., \& Gute, D. M. (2014). Characterizing the low wage immigrant workforce: a comparative analysis of the health disparities among selected occupations in Somerville, Massachusetts. American journal of industrial medicine, 57(5), 516-526.

Pickett, C. L., Silver, M. D., \& Brewer, M. B. (2002). The impact of assimilation and differentiation needs on perceived group importance and judgments of ingroup size. Personality and Social Psychology Bulletin, 28(4), 546-558.

Qayyum, A., Sharif, M. T., Ahmad, A., \& Khan, M. S. (2012). Training \& development practices in national bank of Pakistan. Information Management and Business Review, 4(1), 8.

Reitz, J. G. (2013). Closing the gaps between skilled immigration and Canadian labor markets: Emerging policy issues and priorities Wanted and Welcome? (pp. 147-163): Springer.

Richard A. Posthuma, P., Ayub, N., \& Jehn, K. (2014). When diversity helps performance: Effects of diversity on conflict and performance in workgroups. International Journal of Conflict Management, 25(2), 189-212.

Richard, O. C., Roh, H., \& Pieper, J. R. (2013). The link between diversity and equality management practice bundles and racial diversity in the managerial ranks: Does firm size matter? Human Resource Management, 52(2), 215242.

SamGnanakkan, S. (2010). Mediating role of organizational commitment on HR practices and turnover intention among ICT professionals. Journal of Management Research, 10(1), 39.

Shahzad, K., Bashir, S., \& Ramay, M. I. (2008). Impact of HR practices on perceived performance of university teachers in Pakistan. International review of business research papers, 4(2), 302-315.

Shahzad, K., Sarmad, M., Abbas, M., \& Khan, M. A. (2011). Impact of Emotional Intelligence (EI) on employee's performance in telecom sector of Pakistan. African Journal of Business Management, 5(4), 1225.

Shore, L. M., Randel, A. E., Chung, B. G., Dean, M. A., Ehrhart, K. H., \& Singh, G. (2010). Inclusion and diversity in work groups: A review and model for future research. Journal of management, 0149206310385943.

Stazyk, E. C., Davis, R., \& Liang, J. (2012). Examining the Links between Workforce Diversity, Organizational Goal Clarity, and Job Satisfaction. Paper presented at the APSA 2012 Annual Meeting Paper.

Stets, J. E., \& Burke, P. J. (2000). Identity theory and social identity theory. Social psychology quarterly, 224-237.

Stevens, M. J., Oddou, G., Furuya, N., Bird, A., \& Mendenhall, M. (2006). HR factors affecting repatriate job satisfaction and job attachment for Japanese managers. The International Journal of Human Resource Management, 17(5), 831-841.

Stoermer, S., Hildisch, A. K., Froese, F. J., Tung, R., \& klarsfeld, a. (2016). Culture matters: The influence of national culture on inclusion climate. Cross Cultural \& Strategic Management, 23(2).

Stone, R. J. (2013). Managing human resources: John Wiley and Sons.

Stredwick, J. (2013). An introduction to human resource management: Routledge.

Syed, A. A. S. G., Bhatti, N., Michael, S., Shaikh, F. M., \& Shah, H. (2012). Job satisfaction of faculty members of universities in Pakistan: A case study of university of Sindh-Jamshoro. Modern Applied Science, 6(7), 89.

Teclemichael Tessema, M., \& Soeters, J. L. (2006). Challenges and prospects of HRM in developing countries: testing the HRM-performance link in the Eritrean civil service. The International Journal of Human Resource Management, 17(1), 86-105.

Theodorakopoulos, N., \& Budhwar, P. (2015). Guest Editors' Introduction: Diversity and Inclusion in Different Work Settings: Emerging Patterns, Challenges, and Research Agenda. Human Resource Management, 54(2), 177-197.

Tooksoon, H. M. P. (2011). Conceptual framework on the relationship between human resource management practices, job satisfaction, and turnover. Journal of economic and behaviors studies, 2, 41-49.

Trytten, D. A., Pan, R., \& Foor, M. C. E. (2015). Inclusion or exclusion? The impact of the intersection of team culture and student identity and pathway on team diversity. age, 26, 1.

Williams, S. J., \& Adams, C. A. (2013). Moral accounting? Employee disclosures from a stakeholder accountability perspective. Accounting, Auditing \& Accountability Journal, 26(3), 449-495.

Wright, M. (2016). Gower handbook of internal communication: CRC Press.

Zoogah, D. B., \& Abbey, A. (2010). Cross-cultural experience, strategic motivation and employer hiring preference: An exploratory study in an emerging economy. International Journal of Cross Cultural Management, 10(3), 321-343. 